\title{
SUGGESTED READING
}

\section{FOR}

\section{ANTE-AND \\ POSTNATAL \\ TEACHING}

By ROSEMARY HARTE, M.C:S:P.

There are so many books available relating to the subject that one is sometimes at a loss to know which will be most helpful. Many I have read, and there must be as many again not readily available in this country with which $I$ am unfamiliar. For the purpose of clarity I have grouped books which $I$ have found most meaningful' in my own work into the broad categories of Teaching, Womanhood, Obstetrics, Exercises, Relaxation and General.

It is to be remembered that we are teaching the laywoman and not simply treating her. Depending on our ability to put across our subject follows the measure of our success. Herein lies an answer why so many of our ranks succeed in their work and so many, equally knowledgeable, somehow fail. I am sure that a good book on the technique of teaching is invaluable. There are many on the market and I offer: The Art of Teaching by Gilbert Highet (University Paperbacks), Working With Groups by Josephine Klein (Hutchinson University Library). More specifically: An Approach to Antenatal Teaching by Sheila Kitzinger (National Childbirth Trust). A highly commendable booklet. The approach is largely psychological, an aspect insufficiently stressed in physiotherapy training. Methods of teaching are sound and well explained, and there is an excellent bibliography at the back for those wishing further reading, under specified headings. 
By implication the teacher should understand the pupilWoman. The Second Sex by Simone de Beauvoir (Jonathan Cape), is a veritable milestone in the study of womanhood. The perception, analysis and frank commentary by a controversial and courageous character makes this an invaluable work.

A greater knowledge of obstetrics is required than that afforded by most physiotherapy trainings. Berkeley's Pictorial Midwifery, revised by D. M. Stern (Bailliére, Tindall \& Cox) is text-wise brief and pictorially most informative. A Pocket Obstetrics by Arthur C. H. Bell (Churchill).

In order to meet the physical demands put upon a woman in carrying her baby with minimum strain, delivering it with maximum efficiency, and returning to her physiological norm as soon after birth as possible, a sound physical condition is desirable. This is particularly pertinent in our 20th Century, technological Western civilisation, and specifically in this country. In spite of an increasing tendency overseas not to stress the "number and vigour of the exercises taught"* prenatally, it is my experience that only very isolated cases react adversely compared with the vast majority who appear to derive great benefit. However, the question is conjectural and in my opinion a project for further research. The value of postnatal rehabilitation exercise is not held in question. By definition and training, the physiotherapist is highly equipped to evolve exercises suitable for the needs of the individual or group. For this reason I am disinclined to suggest any specific books on exercise techniques, though Ballet, Yoga, Modern Dance Drama etc., all help to augment the repertoire, contingent on pertinent analysis. The Principles of Exercise Therapy by M. Dena Gardiner (G. Bell \& Sons) is an excellent book for revision, and for further reference: Human Kinetics and Analysing Body Movements by T. McClurg Anderson. Strange that mention is not made of the pleasurable and beneficial effects of using music to induce rhythm and reduce tension and resultant fatigue!

Relaxation is such a profound and subtle discipline, compounded as it is of the physical and the mental, the sensory and the emotional, that the teaching of it, particularly for use under stress, can be highly problematic, and must, of necessity be very individual. These books are recommended: Progressive Relaxation by Edmund Jacobson, M.D. (McGraw-Hill Book Co.). You Must Relax by Edmund Jacobson, M.D. (University of Chicago Press). Release from Nervous Tension by D. H. Fink, M.D. (Unwin Books). Physiological Relaxation by Voluntary Control by Laura Mitchell, M.C.S.P. A gramophone record of a lesson demonstrating this method may be obtained from Recorded Sound Ltd., 27 Bryanston St., London, W.1. Sense Relaxation by Bernard Gunther (Macdonald). A New Way to Relax by Karin Roon.

Finally we come to the welter of books aimed at informing the laywoman on methods of training for childbirth. The similarity between most of them is often so marked that one wonders what moved each subsequent writer to add yet another volume to the already loaded list. Systems vary various stages of labour; facts are often far from accurate; chiefly only in the types of breathing recommended for the and very little original thought and up to date research seems evident. However! At Your Best for Birth and Later by Eileen Montgomery, M.C.S.P. is a little book which I highly recommend. It is packed full of sound information, well tabulated and illustrated. It refrains from the tendency to ooze sickly sentiment, and the thought processes are very much up to the moment. Equally suitable for laywoman or physiotherapist. The Experience of Childbirth by Sheila Kitzinger (Penguin Books) is, in my opinion, a valuable contribution. The author is an artist in expressing herself with a lively humour, and a metaphysical awareness. Psychology-orientated, she explores the psycho-sexual implications of pregnancy and birth in the widest sense, and not just as an isolated incident in the life of a woman. She understands the need for a woman to come to terms with her own body before delivery, and to be able to know and feel the responses of her muscles, thereby facilitating the required control. In this era of low incidence of breastfeeding, her chapter on this subject is excellent. If some feel that her idealistic involvement of the husband is a little unrealistic, that must remain their personal opinion. I found a holism in the knowledge derived from this and the previous book. The Know-How of Pregnancy and Labour by Sylvia Close (John Wright \& Sons Ltd.), a very comprehensive little book written in the question-and-answer form, it covers the ground briefly, fully and efficiently. Sex Development and Maternity by Dr. Pierre Vellay (Hutchinson, 1968), a new and interesting publication. Becoming a Mother by Theodor R. Seidman, M.D. and Marvin H. Albert (Fawcett Publications Inc.). Clear, concise and straightforward. It does not aim at recommending any particular "system", but discusses several of them. Körperschulung Während Schwangerschaft und Rückbildung by Frau Dr. Dagmar Liechtivon Brasch, Frau Edith Risch and Frau Ines Bitterli is of Swiss origin, written in German pending an English translation. It presents some slight but interesting variations on the usual breathing techniques for labour, and some good and well illustrated exercises.

Maternal Breathing in Labour by Dr. R. St.J. Buxton is a very much up to date research booklet put out for the O.A.C.P., and has been reviewed elsewhere in this journal.

In conclusion, it will be noted that most of my recommendations are comparatively recent publications. I am aware of the import of the early contributions of such well known exponents of the discipline under discussion at Lamaze, Grantly Dick Read, Minnie Randall, Helen Heardman and many others. Without their inspiration, research and writings we could not have attained the position enjoyed today. Implicit in present day writing is a knowledge of the works of these men and women, and we owe them a tremendous debt for having prepared the soil for the second generation to analyse and cultivate.

* Recent Advances in Ante- and Postnatal Physiotherapy by Margaret Williams, M.C.S.P., T.M.A.O.T., and J. Odoni, M.C.S.P.

Also $A$ Conservative View of Antenatal Training by P. E. Kennedy, M.C.S.P. 